\title{
Role of Panoramic Radiography in the Identification of Dental Anomalies and Disturbed Development of the Dentition
}

\author{
Cabov Tomislav ${ }^{1}$, Legovic Asja² ${ }^{2}$ Cabov Ercegovic Lucija ${ }^{3}$, Zulijani Ana ${ }^{4}$
}

\begin{abstract}
Aim and objective: This study aimed to determine the prevalence of dental anomalies and impaired dentition development by analyzing panoramic radiographs.

Materials and methods: The study included 1,317 orthopantomograms of children treated in an orthodontic practice. Regarding the development of the dentition, they were divided into five stages: (1) Eruption of the first permanent molars. (2) Replacement of the incisors. (3) Completed replacement of the incisors. (4) Replacement in the supporting zones. (5) Completed replacement of the teeth of the supporting zones.

Results: Dental anomalies were found in $9.5 \%$ of the subjects. In the first stage, $\mathrm{M} 1$ was found to resorb the crown of $\mathrm{m} 2 \mathrm{in} 7.1 \%$ of cases during the eruption. In the second stage, 11 resorbed the adjacent deciduous tooth during the eruption in $17.5 \%$ of the cases. In the third stage, impaired development of incisors was observed in $28.9 \%$ of cases in the maxilla and in $27.9 \%$ in the mandible. In the fourth stage, ectopic position and premature eruption of the germ in segments C-P2 were noted in $20.8 \%$ of teeth in the maxilla and $9.7 \%$ in the mandible. Late mineralization of P2 and ankylosis of $\mathrm{m} 2$ was noted in $3.4 \%$ of cases in the maxilla and $6.5 \%$ in the mandible. In the fifth stage, $11.9 \%$ of $\mathrm{M} 3$ germs were ectopically positioned in the maxilla and $29.5 \%$ in the mandible, $5.9 \%$ of M3 germs were absent in the maxilla, and $6.7 \%$ in the mandible.

Conclusion: Our study showed a similar incidence of various dental anomalies and disturbed dentition development as reported in the literature. The results of this study confirm that the analysis of orthopantomogram is an important and useful element in the diagnosis and treatment plans for a malocclusion.

Clinical significance: Orthopantomogram analysis can be used as a useful element in the diagnosis and treatment plans for a malocclusion. Keywords: Children, Dental anomalies, Developmental disorder, Panoramic radiograph, Prevalence.

World Journal of Dentistry (2021): 10.5005/jp-journals-10015-1836
\end{abstract}

\section{INTRODUCTION}

In addition to the clinical examination and the analysis of plaster casts, the analysis of radiographs is an essential part of orthodontic diagnosis, especially the analysis of the orthopantomogram. Certain findings obtained from the radiographic status (usually 20 intraoral retroalveolar radiographs) are more reliable than findings obtained from the panoramic radiograph., ${ }^{1,2}$ By supplementing the findings of the panoramic radiograph with the findings of 3-4 intraoral radiographs, the reliability of such data approaches obtained from the radiographic status. ${ }^{3}$ Conventional panoramic systems have been replaced by digital systems. There are no significant differences between these two systems in the diagnosis of dental anomalies and problems associated with the position of the third molar. Many factors of exogenous and endogenous origin can affect the occurrence of abnormalities of tooth position and occlusion in the mixed dentition. A radiographic examination can provide important information about dental anomalies in number (hyperdontia and hypodontia), size (microdontia and macrodontia), and crown shape (germination and fusion). Numerous authors have studied their prevalence. ${ }^{4-12}$ Hintze et al. stated that $94 \%$ of children can be excluded from orthodontic therapy by analyzing the orthopantomogram and that it is possible to identify $97 \%$ of those in whom immediate orthodontic therapy is necessary. ${ }^{5} \mathrm{Neal}$ and Bowden attribute slightly less importance to the orthopantomogram for diagnosis and treatment planning. ${ }^{4}$ They found significant data in the orthopantomogram for orthodontic diagnosis and treatment in $26.5 \%$ of 9-10-year-olds.
${ }^{1}$ Department of Oral Surgery, University of Rijeka, Faculty of Dental Medicine, Kresimirova 40, Rijeka, Croatia

${ }^{2}$ Private Orthodontic Practice, Ivana Gorana Kovačića 3, Poreč, Croatia ${ }^{3}$ Department of Periodontology, Dental Polyclinic Zagreb, Ulica Ivana Perkovca 3, Zagreb, Croatia

${ }^{4}$ Department of Oral Surgery, Clinical Hospital Center Rijeka, Kresimirova 40, Rijeka, Croatia

Corresponding Author: Zulijani Ana, Department of Oral Surgery, Clinical Hospital Center Rijeka, Kresimirova 40, Rijeka, Croatia, Phone: +3859158052 06, e-mail: ana.zulijani@gmail.com

How to cite this article: Tomislav C, Asja L, Ercegovic Lucija C, et al. Role of Panoramic Radiography in the Identification of Dental Anomalies and Disturbed Development of the Dentition. World J Dent 2021;12(4):271-277.

Source of support: Nil

Conflict of interest: None

Witcher et al. pointed out a possible insufficient precision in the detection of dental anomalies, such as supernumerary teeth in the anterior maxillary region due to a narrow focal trough or spinal overjet. ${ }^{13}$ They reported significantly higher reliability of using upper anterior occlusal radiographs in this region. The purpose of this study was to determine the prevalence of dental anomalies and certain disturbances in development during different phases of the mixed dentition by analysis of the orthopantomogram. 


\section{Materials and Methods}

The cross-sectional study included 1,317 orthopantomograms (694 girls and 623 boys) of children treated in a private orthodontic practice in Poreč, Croatia, from 2014 to 2019. The age of the subjects ranged from 5 to 15 years, with a mean age of $10.34 \pm 2.17$ years. The study was approved by the Ethics Committees of the Faculty of Medicine, University of Rijeka, and Clinical Hospital Center Rijeka, and written informed consent was obtained from the legal representatives/parents/guardians.

All radiographs were performed using Orthophos 3 Siemens panoramic device with the following parameters: $60-80 \mathrm{kV}, 10 \mathrm{~mA}$, $11.3 \mathrm{~s}$. To minimize possible errors on orthopantomograms, it is most important to place the subject in the correct position in the focus well, exactly as indicated by the manufacturer. ${ }^{14}$ All radiographs in which the contrast of the examined details was unsatisfactory were excluded from the study. Subjects with systemic or syndromal diseases, jaw fractures that affected the natural growth of the permanent dentition, or a history of previous orthodontic treatment were excluded from this study.

The subjects were divided into five stage groups according to the development of the dentition. The distribution of orthopantomogram in terms of sex, age, and stage of dentition development is shown in Table 1.

- On the orthopantomograms of the subjects in stage 1 of dentition development, the prevalence of resorption of the second deciduous molar by $\mathrm{M} 1$ in the eruption and the eruption of $\mathrm{M} 1$ in the space of extracted $\mathrm{m} 2$ (second deciduous molars) were studied.

- On the orthopantomograms of the subjects in the second stage of dentition development, the prevalence of the resorption of the lateral deciduous incisor by the central permanent incisor in eruption and the resorption of the deciduous canine by the lateral permanent incisor in the eruption were studied.

- On the orthopantomograms of the subjects at stage 3 of dentition development, the prevalence of crowding of incisors and diastema between all incisors was studied.

- On the orthopantomograms of the subjects at stage 4 of dentition development, the following prevalence was studied:

- Ectopic position of the canine, first, and second premolars (C, P1, and P2). When subjects of the same age and sex had both homologous tooth germs misaligned on the orthopantomogram with respect to the position of the same tooth, bilateral dystopia was inferred. Unilateral ectopy was inferred if the tooth germ in sagittal position was significantly different from that of the homologous tooth of the same jaw. For the maxillary canine, the ectopic position was inferred if the angle of the longitudinal axis of the tooth with the occlusal plane and the vertical distance of the incisal edge from the occlusal plane were significantly different from the homologous tooth of the same jaw. The ectopic position was also inferred when the crown of the canine was covered by the root of the lateral incisor.

- Premature eruption of a tooth (a situation in which the tooth had erupted and at least half of its root was not mineralized).

- Late mineralization of a tooth (the mineralization of the tooth was late in relation to the homologous tooth or other teeth of the C-P2 segment).

- Ankylosis of a deciduous tooth (the contour of the alveolar bone followed the cementoenamel junction, infraposition of the occlusal plane of the tooth in relation to the homologous tooth or adjacent teeth). After performing the panoramic radiograph during the clinical examination of the subject, the orthodontist noted the pathological features associated with the teeth and supporting structures and attached them to the radiograph. Thus, a record was made of the percussion of the teeth in infraposition.

- On the orthopantomograms of the subjects in the fifth stage of dentition development, the condition of the space after the extraction of the M1, the prevalence of the ectopic position of the $M 3$, and the hypodontia of the M3 were studied.

The prevalence of dental anomalies in the number of teeth (hyperdontia and hypodontia, independent of M3 hypodontia), the size of teeth (microdontia and macrodontia), and the shape of the dental crown (germination and fusion) were studied for all subjects together.

All orthopantomograms were evaluated separately by two orthodontists with over 20 years of experience in evaluating panoramic radiographs. The orthopantomograms were evaluated on the monitor screen without any adjustment. The kappa coefficient was used to determine the degree of agreement. The values of the kappa coefficient ranged from 0.92 to 0.97 . Each orthopantomogram in which there was disagreement in the findings of both examiners was examined separately, and agreement between the two examiners was achieved in a joint examination. The significance of the difference between the variables examined and the percentages between the maxilla and mandible at specific stages of dentition development was determined using a $t$-test for proportions. The level of statistical significance was determined at the level $p<0.05$.

Table 1: Distribution of orthopantomograms by sex and stage of dentition development

\begin{tabular}{|c|c|c|c|c|c|}
\hline \multicolumn{2}{|c|}{ Development of dentition } & \multirow{2}{*}{$\frac{\text { Age range }}{5-8}$} & \multirow{2}{*}{$\frac{\text { Boys, } N}{76}$} & \multirow{2}{*}{$\frac{\text { Girls, N }}{78}$} & \multirow{2}{*}{$\frac{\text { Total, } N}{154}$} \\
\hline Stage 1 & Eruption of the first permanent molars in progress (M1) & & & & \\
\hline Stage 2 & Exchange of incisors in progress & $5-9$ & 114 & 114 & 228 \\
\hline Stage 3 & $\begin{array}{l}\text { Exchange of incisors complete, but the exchange of teeth in C-P2 } \\
\text { segments not commenced (deciduous canine and deciduous } \\
\text { molars) }\end{array}$ & $8-10$ & 157 & 183 & 340 \\
\hline Stage 4 & $\begin{array}{l}\text { Exchange of incisors complete, exchange of teeth in C-P2 segments } \\
\text { in progress }\end{array}$ & $8-13$ & 200 & 214 & 414 \\
\hline Stage 5 & Exchange of teeth in C-P2 segments complete & $11-14$ & 76 & 105 & 181 \\
\hline Total & & & 623 & 694 & 1,317 \\
\hline
\end{tabular}




\section{Results}

The results of the study are presented in Tables 2 to 7. Table 2 shows the prevalence of dental anomalies. Dental anomalies were found in $9.5 \%$ of the subjects. The most common was hypodontia (6.3\%), followed by hyperdontia (1.5\%), microdontia (1.4\%), germination $(0.15 \%)$, and fusion $(0.07 \%)$.

Table 3 shows the prevalence of impaired development of dentition in stage 1. It was found that the second deciduous molar was resorbed in $4.5 \%$ of the subjects in the maxilla and $2.6 \%$ in the mandible $(p=0.169)$ during eruption M1. The first permanent molar erupted into the space of prematurely lost $\mathrm{m} 2$ in $18.5 \%$ of the subjects in the mandible and $12.9 \%$ in the maxilla ( $p=0.057)$.

Table 4 shows the prevalence of impaired development of dentition in stage 2. It was found that during the eruption, the permanent incisor resorbed the adjacent deciduous tooth in $13.6 \%$ of the subjects in the maxilla and $3.9 \%$ in the mandible $(p=0.003)$. This occurred more frequently in the maxilla during the eruption of the lateral incisor than during the eruption of the central incisor (8.3 vs $5.3 \% ; p=0.195$ ).

Table 5 shows the prevalence of impaired development of the dentition at stage 3. Impaired development during the eruption of the incisors was observed in $28.9 \%$ of the subjects in the maxilla and $27.9 \%$ in the mandible ( $p=0.772)$. Crowding of incisors was more common in the maxilla (15.6 vs $11.8 \% ; p=0.133)$, and spacing was more common in the mandible (16.2 vs $13.2 \% ; p=0.267$ ).

Table 2: Prevalence of dental anomalies

\begin{tabular}{lrl}
\hline Dental anomalies & $N$ & $\%^{*}$ \\
\hline Hypodontia & 83 & 6.3 \\
Hyperdontia & 20 & 1.5 \\
Microdontia & 19 & 1.4 \\
Germination & 2 & 0.15 \\
Fusion & 1 & 0.07 \\
Total & 125 & 9.5 \\
\hline
\end{tabular}

*Percentage shares are determined in relation to the total number of subjects $(N=1,317)$

Table 3: Prevalence of disturbed development of dentition in stage 1

\begin{tabular}{lrrrrrr}
\hline & \multicolumn{3}{c}{ Maxillary } & & \multicolumn{3}{c}{ Mandible } \\
\cline { 2 - 3 } \cline { 6 - 7 } Analyzed variables & $N$ & \multicolumn{1}{c}{$\%$} & & $N$ & \multicolumn{1}{c}{$\%$} \\
\hline M1 during eruption resorbed M2* & 7 & 4.5 & & 4 & 2.6 \\
M1 erupted in the space of the & 40 & 12.9 & & 57 & 18.5
\end{tabular}
extracted $M 2^{* *}$

*Percentage shares are determined in relation to the total number of subjects in stage $1(N=154)$

**Percentage shares are determined in relation to the total number of teeth in stage $1(N=308)$

Table 4: Prevalence of disturbed development of dentition in stage 2

\begin{tabular}{|c|c|c|c|c|}
\hline \multirow[b]{2}{*}{ Analyzed variables } & \multicolumn{2}{|c|}{ Maxillary } & \multicolumn{2}{|c|}{ Mandible } \\
\hline & $N$ & $\%$ & $N$ & $\%$ \\
\hline $\begin{array}{l}11^{*} \text { During eruption resorbed i2 } \\
\text { crown }\end{array}$ & 12 & 5.3 & & \\
\hline $12^{\$}$ During eruption resorbed $c^{\# \#}$ crown & 19 & 8.3 & 9 & 3.9 \\
\hline Total & 31 & 13.6 & 9 & 3.9 \\
\hline
\end{tabular}

$11^{*}$ central permanent incisor, ${ }^{\#}{ }^{\#}$ lateral deciduous incisor, $12^{\$}$ lateral permanent incisor, $\mathrm{c}^{\# \#}$ deciduous canine

*Percentage shares are determined in relation to the total number of subjects in stage $2(N=228)$
Table 6 shows the prevalence of impaired dentition development in stage 4 . The most common disorders of dentition development during tooth change in segments C-P2 were ectopic tooth position and premature eruption. Both disorders were more frequent in the maxilla (ectopic tooth position: 10.9 vs $5.6 \% ; p<0.001$; premature eruption of teeth: 9.9 vs $4.1 \% ; p<0.001)$. Late mineralization of P2 was found in $3.1 \%$ of subjects in the mandible and $2.2 \%$ in the maxilla ( $p=0.420$ ), and ankylosis of $\mathrm{m} 2$ in $1.2 \%$ of subjects in the maxilla and $3.4 \%$ in the mandible $(p=0.035)$.

Table 7 shows the prevalence of impaired dentition development at stage 5 . The extraction spaces of M1 were narrow or closed in $19 \%$ of the subjects in the mandible and in $14.2 \%$ in the maxilla ( $p$ $=0.292$ ). The germ of the lower M3 was more frequently positioned dytopically in the mandible than in the maxilla (29.5 vs $11.9 \%$; $p$ $=0.001$ ). The germ of the mandibular M3 was absent in $6.7 \%$ of subjects and that of the maxillary M3 in $5.9 \%$ of subjects $(p=0.806)$.

\section{Discussion}

In this study, the prevalence of dental anomalies and certain growth disorders during the mixed dentition was investigated by analyzing the orthopantomogram. Dental anomalies were found in $9.5 \%$ of the subjects. Stahl et al. and Thongudomporn and Freer

Table 5: Prevalence of disturbed development of dentition in stage 3

\begin{tabular}{|c|c|c|c|c|}
\hline \multirow[b]{2}{*}{ Analyzed variables } & \multicolumn{2}{|c|}{ Maxillary } & \multicolumn{2}{|c|}{ Mandible } \\
\hline & $N$ & $\%$ & $N$ & $\%$ \\
\hline Crowding of incisors* & 53 & 15.6 & 40 & 11.8 \\
\hline Diastema between incisors* & 45 & 13.2 & 55 & 16.2 \\
\hline Total & 98 & 28.9 & 95 & 27.9 \\
\hline
\end{tabular}

*Percentage shares are determined in relation to the total number of subjects in stage $3(N=340)$

Table 6: Prevalence of disturbed development of dentition in stage 4

\begin{tabular}{lllllll}
\hline & \multicolumn{3}{c}{ Maxillary } & & \multicolumn{3}{c}{ Mandible } \\
\cline { 2 - 3 } \cline { 5 - 6 } Analyzed variables & $N$ & $\%$ & & $N$ & $\%$ \\
\hline $\begin{array}{l}\text { Ectopic position of the teeth of } \\
\text { C-P2** segment }\end{array}$ & 270 & 10.9 & & 139 & 5.6 \\
$\begin{array}{l}\text { Premature eruption of the teeth } \\
\text { of C-P2** segment }\end{array}$ & 247 & 9.9 & & 102 & 4.1 \\
$\begin{array}{l}\text { Late mineralization of P2* } \\
\text { Ankylosis m2* }\end{array}$ & 9 & 2.2 & & 13 & 3.1 \\
\cline { 1 - 2 } & 5 & 1.2 & & 14 & 3.4 \\
\hline
\end{tabular}

*Percentage shares are determined in relation to the total number of subjects in stage $4(N=414)$

**Percentage shares are determined in relation to the total number of teeth in stage $3(N=2,484)$

Table 7: Prevalence of disturbed development of dentition in stage 5

\begin{tabular}{lrrrrr}
\hline & \multicolumn{3}{c}{ Maxillary } & & \multicolumn{3}{c}{ Mandible } \\
\cline { 2 - 3 } \cline { 5 - 6 } Analyzed variables & $N$ & $\%$ & & $N$ & $\%$ \\
\hline $\begin{array}{l}\text { Space of the extracted M1 narrow } \\
\text { or closed* }\end{array}$ & 38 & 14.2 & & 51 & 19.0 \\
Ectopic position of germ & & & & \\
Agenesis M3* $^{*}$ & 32 & 11.9 & & 79 & 29.5 \\
& 8 & 5.9 & & 9 & 6.7 \\
\hline
\end{tabular}

*Percentage shares are determined in relation to the total number of subjects in stage $4(N=134)$

**Percentage shares are determined in relation to the total number of teeth in stage $3(N=268)$ 
found significantly higher prevalence (40.8 and $30.8 \%$ ) and studied more dental anomalies than the present study. ${ }^{8,11}$ Pallikaraki et al. found anomalies of teeth and jaws in $18.8 \%$ of subjects by analyzing panoramic radiographs. ${ }^{15}$ They found 224 developmental dental anomalies on 1,200 radiographs. Considering amelogenesis imperfecta, which was not investigated in this study, Altug-Atac and Erdem found a significantly lower prevalence of dental anomalies in a Turkish population, $5.6 \% .{ }^{16}$ The wide variation may be attributed to different sample size, age range, and included dental anomalies.

The findings of hyperdontia, germination, and fusion obtained in this study confirm the findings of other authors. ${ }^{17,18}$ Hyperdontia was $1.5 \%$ of all subjects, which is in the same range (1.2-3\%) in the review study by Anthonappa et al. ${ }^{19}$ According to Laganà et al. and Stahl et al. mesiodens was the most common form of supernumerary teeth in non-orthodontic and orthodontic patients, with a higher prevalence in orthodontic patients. ${ }^{11,20}$ Regarding the prevalence of hypodontia (6.3\%), a higher prevalence was found by Vahid-Dastjerdi et al. than in the study, $9.1 \%$, in a retrospective study of 1,751 subjects. ${ }^{21}$ In a review by Rakhshan, the prevalence of hypodontia in the permanent dentition, excluding M3, ranged from 0.15 to $16.2 \% .^{22}$ Baccetti significantly associated second premolar hypodontia with dental anomalies and disorders of dentition development, microdontia of maxillary lateral incisors, ankylosis of deciduous molars, enamel hypoplasia, and palatally displaced teeth. ${ }^{23,24}$

In the study, microdontia and peg-shaped lateral incisors were considered as anomalies and were found in $1.4 \%$ of the subjects. Both anomalies were found in $5.2 \%$ of children by Albashaireh and Khader. ${ }^{25}$ Hua et al. reported the average prevalence of peg-shaped teeth in the general population to be $1.8 \%$, similar to our study, and the most affected were the maxillary lateral incisors, concluded Altug-Atac and Erdem. ${ }^{16,26}$ The prevalence of microdontia was reported in the range of $0.5-2.6 \%$ and also the most affected were the maxillary lateral incisors by Kjær. ${ }^{16,27-29}$

Ectopic eruption of $\mathrm{M} 1$, in which this tooth resorbs the crown of the second deciduous molar during the eruption, was found in $7.1 \%$ of the subjects, with an insignificant prevalence in the maxilla relative to the mandible. This impaired tooth development shows a variable prevalence from 2 to $6 \% .^{30-32}$ The largest study on a sample of 8,041 children, conducted by Salbach et al. diagnosed this disorder in a significantly lower number of subjects (1.3\%) and more frequently in the maxilla, in agreement with the data of other authors, without preference for the left or right side. ${ }^{32-35}$ Chintakanon and Boonpinon reported ectopic eruption of M1 in a significantly smaller number of subjects $(0.75 \%)$ with similar prevalences for $\mathrm{M} 1$ in the mandible and maxilla. ${ }^{35}$ Barberia-Leache et al. found ectopic eruption of M1 with resorption of the $\mathrm{m} 2$ crown in $4.3 \%$ of children, citing incorrect direction of eruption and also increased mesiodistal diameter of the M1 crown as the main reason. ${ }^{30,32-35}$ Other etiologic factors that may lead to ectopic eruption have been reported in the literature to be the inadequate length of the dental arch and a growth deficit in the posterior region. ${ }^{33}$ Bjerklin et al. and Baccetti relate this disorder to other genetically determined disorders in dentition development. ${ }^{24,34}$ Bjerklin et al. link this to infraocclusion and ankylosis of $\mathrm{m} 2$ and ectopic eruption of the upper canine, and Baccetti mentions rotation of the upper lateral incisor in addition to the above. ${ }^{24,34}$ In addition, the study by Salbach et al. found a significant association of ectopic eruption of the maxillary first molar with crowding, lateral malocclusion, and mandibular prognathism. ${ }^{33}$ A relationship between ectopic eruption and one or more other dental anomalies may be inferred. In Istria and other regions, premature loss of deciduous teeth of the supporting zone is common. ${ }^{36,37}$ In $12.9 \%$ of maxillary segments and $18.5 \%$ of mandibular segments, $\mathrm{M} 1$ erupts in its place due to premature loss of $\mathrm{m} 2$. Apart from the fact that the premature loss of $\mathrm{m} 2$ due to the mesial eruption of $\mathrm{M} 1$ destroys the harmony of the area and width of the crowns of C, P1, and P2, it also provokes an earlier eruption of $\mathrm{M} 2$, which further disturbs the harmony. ${ }^{38,39}$ The state of health of $\mathrm{M} 1$ teeth in the Istrian region is poor, and therefore they are often extracted prematurely. ${ }^{37}$ The consequences are reflected in the position of the adjacent teeth, where they are more pronounced in the maxilla and also in the occlusion. ${ }^{40}$

The normal position of the incisor in the dental arch depends on many factors that have long-term effects. Some act before the replacement of the incisors, some act during the replacement, and some act after the replacement of the incisors, when the normal symmetrical positioning of the incisors should take place. ${ }^{38}$ Often, disproportions of the space in the dental arch and the width of the crown of the erupting incisors result in a situation where the tooth resorbs the adjacent tooth during the eruption. These phenomena were found to be significantly greater in the maxilla than in the mandible $(p=0.003)$. In the maxilla, 12 resorbed the crown of the deciduous canine during eruption insignificantly more often than 11 resorbed the crown of the lateral deciduous incisor $(p=0.195)$. These disturbances are predictors of crowding in the incisor region. Although in the literature, data on crowding of incisors show a wide variation in prevalence (28.4-52.1\%) depending on the measured spatial discrepancies, it is considered to be the most common anomaly with the increase in permanent dentition. ${ }^{41-45}$ In the present study, crowding of incisors was found to be insignificantly more frequent in the maxilla relative to the mandible $(p=0.133)$. Other authors found more frequent crowding of incisors in the mandible. ${ }^{8,43,45}$ However, Keski-Nisula et al., Borzabadi-Farahani et al., and Gelgör et al. found a lower prevalence of crowding in mandible but significantly higher in the maxilla. ${ }^{44,46,47}$ Spacing between incisors was found to be insignificantly lower in the maxilla than the mandible ( $p=0.267$ ). Thilander et al. arrived at similar data, and a significantly greater prevalence of spacing was found by Bässler-Zeltman et al. ${ }^{42,48}$

Within the supporting zone, two teeth appear very frequently ectopically in the dental arch due to either genetic instability-P2, or complications during eruption-upper canine, or whose mineralization and eruption time deviate from normal. ${ }^{49}$ The ectopic position of the tooth germ was found significantly more frequently in the maxilla than in the mandible $(p<0.001)$. Bjerklin et al. found atypical germ position in $12.2 \%$ and displaced teeth in $7 \%$ of subjects. ${ }^{34}$ Stemm also found frequently malpositioned lower premolars (P1 14.67\%, P2 41.0\%). ${ }^{50}$ The author reported that many of them were spontaneously upright in normal occlusion during development. According to literature data, the upper canine is ectopically placed in $0.92-4.3 \%$ of subjects. ${ }^{51}$ In addition to space loss due to premature loss of supporting zone teeth, permanent successors also erupt prematurely due to periapical processes on deciduous teeth. Also, in this study, there was a significantly higher percentage of a premature eruption of teeth of the C-P2 segments of the maxilla compared with the percentage in the mandible $(p<$ $0.001)$. Late mineralization of the $P 2$, decreased mesiodistal diameter 
of the dental crown, the ectopic position of the germ, late eruption, decreased vertical growth of the alveolar process of the segment, infraocclusion of the deciduous tooth, and atypical position of the adjacent teeth are microsymptoms of hypodontia. ${ }^{49,52}$ Ankylosis of the deciduous molars was found in $4.5 \%$ of subjects, with significant prevalence in the mandible (3.4 vs $1.2 \% ; p=0.035$ ). Kurol found deciduous molar infraocclusion in $8.9 \%$ of subjects, with a tenfold higher incidence in the mandible. ${ }^{53} \mathrm{~A}$ similar incidence has been reported in previous studies, with significant variations likely due to the different ages of subjects at inclusion criteria. ${ }^{54,55}$ A significant association of deciduous molar infraocclusion in the mandible and atypical maxillary canine position was reported by Laganà et al. ${ }^{20}$ Shalish et al. suggested infraocclusion as an early marker of dental agenesis and palatally displaced canines. ${ }^{56}$ Increased prevalence of ectopically placed maxillary canines was found in correlation with hypodontia of the maxillary lateral incisor, but even more frequently in correlation with hypodontia of the mandibular P2. ${ }^{57}$

The ectopic position of the M3 germ is significantly more frequent in the mandible $(p<0.001)$. According to some authors, with the development of $M 3$, there is a possibility that the ectopic position will be corrected. ${ }^{58,59}$ In the absence of space, the ectopic position of the germ is the main reason for M3 impaction, the prevalence of which ranges from 9.5 to $39 \% .6,58,60$

Agenesis of M3 was evaluated in this study after the age of thirteen years, although in the literature its initial mineralization was found as early as seven years. ${ }^{61}$ In the subjects of this study, it was found in $12.7 \%, 5.9 \%$ in the maxilla, and $6.7 \%$ in the mandible. In the other studies, the prevalence was reported between 12.7 and $41 \%$, varying according to the population and age of the subjects. In addition, agenesis showed a greater incidence in the maxilla. ${ }^{62}$ There have been studies suggesting associations between agenesis and other dental anomalies, reduced size, and hypodontia of other permanent teeth. ${ }^{63,64}$

\section{Conclusion}

Our study showed a similar incidence of various dental anomalies and disturbed dentition development as reported in the literature. The results of this study confirm that the analysis of the orthopantomogram is an important and useful element in the diagnosis and treatment plans for a malocclusion.

\section{Clinical Significance}

Orthopantomogram analysis can be used as a useful element in diagnosis and treatment plans for dental anomalies and malocclusion.

\section{Ethics Declarations}

This study was approved by the Ethics Committees of Faculty of Medicine, University of Rijeka, and Clinical Hospital Center Rijeka.

"All procedures followed were in accordance with the ethical standards of the responsible committee on human experimentation (institutional and national) and with the Helsinki Declaration of 1975, as revised in 2008 (5). Informed consent was obtained from all patients for being included in the study."

The study included children and adolescents ages below 18 years. Written informed consent was obtained from the legally authorized representatives/parents/guardians. Legally authorized representatives/parents/guardians could refuse their child's participation, and participation was voluntary. All obtained data were kept strictly confidential.

\section{References}

1. Akkaya N, Kansu O, Kansu H, et al. Comparing the accuracy of panoramic and intraoral radiography in the diagnosis of proximal caries. Dentomaxillofac Radiol 2006;35(3):170-174. DOI: 10.1259/ $\mathrm{dmfr} / 26750940$.

2. Molander B. Panoramic radiography in dental diagnostics. Swed Dent J Suppl 1996;119:1-26.

3. Molander B, Ahlqwist M, Gröndahl HG. Panoramic and restrictive intraoral radiography in comprehensive oral radiographic diagnosis. Eur J Oral Sci 1995;103(4):191-198. DOI: 10.1111/j.1600-0722.1995. tb00159.x.

4. Neal JJ, Bowden DE. The diagnostic value of panoramic radiographs in children aged nine to ten years. Br J Orthod 1988;15(3):193-197. DOI: 10.1179/bjo.15.3.193.

5. Hintze $\mathrm{H}$, Wenzel A, Williams S. Diagnostic value of clinical examination for the identification of children in need of orthodontic treatment compared with clinical examination and screening pantomography. Eur J Orthod 1990;12(4):385-388. DOI: 10.1093/ ejo/12.4.385.

6. Capelli Jr J. Mandibular growth and third molar impaction in extraction cases. Angle Orthod 1991;61(3):223-229. DOI: 10.1043/0003-3219(1991)0612.0.CO;2.

7. Bjerklin K. Ectopic eruption of the maxillary first permanent molar. An epidemiological, familial, aetiological and longitudinal clinical study. Swed Dent J Suppl 1994;100:1-66.

8. Thongudomporn U, Freer TJ. Prevalence of dental anomalies in orthodontic patients. Aus Dent J 1998;43(6):395-398.

9. Cholitgul W, Drummond BK. Jaw and tooth abnormalities detected on panoramic radiographs in New Zeland children aged 10-15 years. N Z Dent J 2000;96(423):10-13.

10. Stahl F, Grabowski R. Maxillary canine displacement and genetically determined predisposition to disturbed development of the dentition. J Orofac Orthop 2003;64(3):167-177. DOI: 10.1007/s00056003-0221-y.

11. Stahl F, Grabowski R, Wigger K. Epidemiological significance of Hoffmeister's "genetically determined predisposition to disturbed development of the dentition". J Orofac Orthop 2003;64(4):243-255. DOI: 10.1007/s00056-003-0220-z.

12. Ezoddini AF, Sheikhha MH, Ahmadi H. Prevalence of dental developmental anomalies: a radiographic study. Community Dent Health 2007;24(3):140-144.

13. Witcher TP, Brand S, Gwilliam JR, et al. Assessment of the anterior maxilla in orthodontic patients using upper anterior occlusal radiographs and dental panoramic tomography: a comparison. Oral Surg Oral Med Oral Pathol Oral Radiol Endod 2010;109(5):765-774. DOI: 10.1016/j.tripleo.2009.10.016.

14. Yeo DK, Freer TJ, Brockhurst PJ. Distortions in panoramic radiographs. Austr Orthod J 2002;18(2):92-98.

15. Pallikaraki G, Sifakakis I, Gizani S, et al. Developmental dental anomalies assessed by panoramic radiographs in a Greek orthodontic population sample. Eur Arch Paediatr Dent 2019;21(2):223-228. DOI: 10.1007/s40368-019-00476-y.

16. Altug-Atac AT, Erdem D. Prevalence and distribution of dental anomalies in orthodontic patients. Am J Orthod Dentofacial Orthop 2007;131(4):510-514. DOI: 10.1016/j.ajodo.2005.06.027.

17. Bäckman B, Wahlin YB. Variations in number and morphology of permanent teeth in 7-year-old swedish children. Int J Paediatr Dent 2001;11(1):11-17. DOI: 10.1046/j.1365-263x.2001.00205.x.

18. Hamasha AA, Al-Khateeb T. Prevalence of fused and geminated teeth in Jordanian adults. Quintessence Int 2004;35(7):556-559.

19. Anthonappa RP, King NM, Rabie AB. Prevalence of supernumerary teeth based on panoramic radiographs revisited. Pediatr Dent 2013;35(3):257-261. 
20. Laganà G, Venza N, Borzabadi-Farahani A, et al. Dental anomalies: prevalence and associations between them in a large sample of non-orthodontic subjects, a cross-sectional study. BMC Oral Health 2017;17(1):62. DOI: 10.1186/s12903-017-0352-y.

21. Vahid-Dastjerdi E, Borzabadi-Farahani A, Mahdian M, et al. Nonsyndromic hypodontia in an Iranian orthodontic population. J Oral Sci 2010;52(3):455-461. DOI: 10.2334/josnusd.52.455.

22. Rakhshan V. Congenitally missing teeth (hypodontia): a review of the literature concerning the etiology, prevalence, risk factors, patterns and treatment. Dent Res J 2015;12(1):1-13. DOI: 10.4103/17353327.150286.

23. Baccetti T. A clinical and statistical study of etiologic aspects related to associated tooth anomalies in number, size, and position. Minerva Stomatol 1998;47(12):655-663.

24. Baccetti T. Tooth anomalies associated with failure of eruption of first and second permanent molars. Am J Orthod Dentofacial Orthop 2000;118(6):608-610. DOI: 10.1067/mod.2000.97938.

25. Albashaireh ZS, Khader YS. The prevalence and pattern of hypodontia of the permanent teeth and crown size and shape deformity affecting upper lateral incisors in a sample of Jordanian dental patients. Community Dent Health 2006;3(4):239-243.

26. Hua F, He H, Ngan $\mathrm{P}$, et al. Prevalence of peg-shaped maxillary permanent lateral incisors: a meta-analysis. Am J Orthod Dentofacial Orthop 2013;144(1):97-109. DOI: 10.1016/j.ajodo.2013.02.025.

27. Kazanci F, Celikoglu M, Miloglu O, et al. Frequency and distribution of developmental anomalies in the permanent teeth of a Turkish orthodontic patient population. J Dent Sci 2011;6(2):82-89. DOI: 10.1016/j.jds.2011.03.003.

28. Fekonja A. Prevalence of dental developmental anomalies of permanent teeth in children and their influence on esthetics. J Esthet Restor Dent 2017;29(4):276-283. DOI: 10.1111/jerd.12302.

29. Kjær I. Can the location of tooth agenesis and the location of initial bone loss seen in juvenile periodontitis be explained by neural developmental fields in the jaws? Acta Odontol Scand 1997;55(1):7072. DOI: 10.3109/00016359709091945.

30. Barberia-Leache E, Suarez-Clúa MC, Saavedra-Ontiveros D. Ectopic eruption of the maxillary first permanent molar: characteristics and occurrence in growing children. Angle Orthod 2005;75(4):610-615. DOI: 10.1043/0003-3219(2005)75[610:EEOTMF]2.0.CO;2.

31. Bjerklin K, Kurol J. Prevalence of ectopic eruption of the maxillary first permanent molar. Swed Dent J 1981;5(1):29-34.

32. Kimmel NA, Gellin ME, Bohannan HM, et al. Ectopic eruption of maxillary first permanent molars in different areas of the United States. ASDC J Dent Child 1982;49(4):294-299.

33. Salbach A, Schremmer B, Grabowski R, et al. Correlation between the frequency of eruption disorders for first permanent molars and the occurrence of malocclusions in early mixed dentition. J Orofac Orthop 2012;73(4):298-306. DOI: 10.1007/s00056-012-0083-2.

34. Bjerklin K, Kurol J, Valentin J. Ectopic eruption of maxillary first permanent molar and association with other tooth and developmental disturbances. Eur J Orthod 1992;14(5):369-375. DOI: 10.1093/ejo/14.5.369.

35. Chintakanon K, Boonpinon P. Ectopic eruption of the permanent molars: prevalence and etiologic factors. Angle Orthod 1998;68(2):153-160. DOI: 10.1043/0003-3219(1998)0682.3.CO;2.

36. Schopf P. Indication for and frequency of early orthodontic therapy or interceptive measures. J Orofac Orthop 2003;64(3):186-200. DOI: 10.1007/s00056-003-0234-6.

37. Legovic M. Health condition of first permanent molars in patients with mixed dentition from a region of Istra. Acta Stomatol Croat 1979;13(2):62-67.

38. Czeholinski JA, Kahl B, Schwarze CW. Early deciduous tooth loss-the mature or immature eruption of their permanent successors. Fortschr Kieferorthop 1994;55(2):54-60. DOI: 10.1007/BF02174357.

39. Van der Linden F, Duterloo H. Atlante Dello Sviluppo Della Dentizione Umana. Padova: Ed Piccin; 1983.
40. Laine $T$, Hausen $H$. Space anomalies, missing permanent teeth and orthodontic treatment. Angle Orthodont 1985;55(3):242-250. DOI: 10.1043/0003-3219(1985)0552.0.CO;2.

41. Proffit WR, Fields Jr HW, Moray LJ. Prevalence of malocclusion and orthodontic treatment need in the United States: estimates from NHANES III survey. Int J Adult Orthodon Orthognath Surg 1998;13(2):97-106.

42. Thilander B, Pena L, Infante C, et al. Prevalence of malocclusion and orthodontic treatment need in children and adolescents in Bogota, Columbia. An epidemiological study related to different stages of dental development. Eur J Orthod 2001;23(2):153-167. DOI: 10.1093/ ejo/23.2.153.

43. Tausche E, Luck O, Harzer W. Prevalence of malocclusions in the early mixed dentition and orthodontic treatment need. Eur J Orthod 2004;26(3):237-244. DOI: 10.1093/ejo/26.3.237.

44. Borzabadi-Farahani A, Borzabadi-Farahani A, Eslamipour F. Malocclusion and occlusal traits in an urban Iranian population. An epidemiological study of 11- to 14-year-old children. Eur J Orthod 2009;31(5):477-484. DOI: 10.1093/ejo/cjp031.

45. Yu X, Zhang H, Sun L, et al. Prevalence of malocclusion and occlusal traits in the early mixed dentition in Shanghai, China. Peer J 2019;7:e6630. DOI: 10.7717/peerj.6630.

46. Keski-Nisula K, Lehto R, Lusa V, et al. Occurrence of malocclusion and need of orthodontic treatment in early mixed dentition. Am J Orthod Dentofacial Orthop 2003;124(6):631-638. DOI: 10.1016/j. ajodo.2003.02.001.

47. Gelgör IE, Karaman Al, Ercan E. Prevalence of malocclusion among adolescents in central anatolia. Eur J Dent 2007;1(3):125-131. DOI: 10.1055/s-0039-1698327.

48. Bässler-Zeltman S, Kretschmer I, Göz G. Malocclusion and the need for orthodontic treatment in 9-year old children. Survey based on the Swedish National Board of Health and Welfare Scale. J Orofac Orthop 1998;59(4):193-201. DOI: 10.1007/BF01579163.

49. Kahl B, Schwarze CW. Late mineralisation of premolars in relation to orthodontic diagnosis and therapy. Fortschr Kieferorthop 1986;47(3):234-244. DOI: 10.1007/BF02168848.

50. Stemm RM. The frequency of malposed lower premolar teeth. Angle Orthod 1997;41(2):157-158.

51. Crescini A. Trattamento Chirurgico-Ortodontico Dei Canini Inclusi. Bologna: Martina Ed; 1998.

52. Schulze $\mathrm{CH}$. Anomalien und Missbildungen der menschlichen Zähne. Berlin-Chicago-London-Säo Paulo-Tokio: Quintessenz; 1987.

53. Kurol J. Infraocclusion of primary molars: an epidemiological and familial study. Community Dent Epidemiol 1981;9(2):94-102. DOI: 10.1111/j.1600-0528.1981.tb01037.x.

54. Krakowiak FJ. Ankylosed primary molars. ASDC J Dent Child 1978;45(4):288-292.

55. Jenkins FR, Nichol RE. Atypical retention of infraoccluded primary molars with permanent successor teeth. Eur Arch Paediatr Dent 2008;9(1):51-55. DOI: 10.1007/BF03321597.

56. Shalish M, Peck S, Wasserstein A, et al. Increased occurrence of dental anomalies associated with infraocclusion of deciduous molars. Angle Orthod 2010;80(3):440-445. DOI: 10.2319/062609-358.1.

57. Al-Abdallah M, AlHadidi A, Hammad $M$, et al. Prevalence and distribution of dental anomalies: a comparison between maxillary and mandibular tooth agenesis. Am J Orthod Dentofacial Orthop 2015;148(5):793-798. DOI: 10.1016/j.ajodo.2015.05.024.

58. Hattab FN. Positional changes and eruption of impacted mandibular third molars in young adults. A radiographic 4-years follow-up study Oral Surg Oral Med Oral Pathol Oral Radiol Endod 1997;84(6):604-608. DOI: 10.1016/s1079-2104(97)90359-0.

59. Steinhardt J, Mertins J, Mertins H. Röntgenologische Befunde zur Keimlage und zum Durchbruch der dritten Molaren. Forschr Kieferorthop 1988;49(2):152-159. DOI: 10.1007/BF02163374.

60. Behbehani F, Årtun J, Thalib L. Prediction of mandibular thirdmolar impaction in adolescent orthodontic patients. Am J 
Orthod Dentofacial Orthop 2006;130(1):47-55. DOI: 10.1016/j. ajodo.2006.03.002.

61. Jung $\mathrm{YH}, \mathrm{ChoBH}$. Radiographic evaluation of third molar development in 6- to 24-year-olds. Imaging Sci Dent 2014;44(3):185-191. DOI: 10.5624/isd.2014.44.3.185.

62. Sujon MK, Alam MK, Rahman SA. Prevalence of third molar agenesis: associated dental anomalies in non-syndromic 5923 patients. PLoS ONE 2016;11(8):e0162070. DOI: 10.1371/journal.pone.0162070.
63. Garn SM, Lewis AB. The gradient and pattern of crown-size reduction in simple hypodontia. Angle Orthod 1970;40(1):51-58. DOI: 10.1043/0003-3219(1970)0402.0.CO;2.

64. Celikoglu M, Bayram M, Nur M. Patterns of third-molar agenesis and associated dental anomalies in an orthodontic population. Am J Orthod Dentofacial Orthop 2011;140(6):856-860. DOI: 10.1016/j. ajodo.2011.05.021. 